\title{
Penggunaan Media Flashcard untuk Mengenalkan Matematika Permulaan pada Anak Usia Dini
}

\author{
Idzni Azhima $^{\bowtie}$, R. Sri Martini Meilanie ${ }^{2}$, Agung Purwanto ${ }^{3}$ \\ Pendidikan Anak Usia Dini, Universitas Negeri Jakarta \\ DOI: $10.31004 /$ obsesi.v5i2.1091
}

\begin{abstract}
Abstrak
Kemampuan anak usia dini dalam memahami matematika permulaan masih tergolong rendah. Hal ini disebabkan karena proses belajar pada anak usia dini tidak dilakukan sesuai dengan perkembangan usia anak. Tujuan dari penelitian ini yaitu untuk mendeskripsikan penggunaan media flashcard dalam mengenalkan matematika permulaan pada anak usia dini. Adapun metode penelitian yang digunakan dalam penelitian ini yaitu menggunakan teknik studi literatur dengan mengkaji beberapa literatur dari berbagai sumber yang ada yang disesuaikan dengan topik penelitian. Teknik analisis data yang digunakan dalam penelitian ini terdiri dari tiga tahap, yaitu reduksi data, penyajian data, dan verifikasi atau penarikan kesimpulan. Hasil penelitian yang diperoleh dalam penelitian ini yaitu penggunaan media flashcard dapat membantu anak memahami matematika permulaan seperti konsep bilangan dan geometri. Hal ini dikarenakan media flashcard menampilkan gambar bentuk-bentuk dasar geometri yang memiliki jumlah sesuai dengan lambang bilangan 1-10, sehingga anak mudah untuk memahami makna angka 1-10 berdasarkan jumlah kuantitas dari gambar bentuk dasar geometri yang ditampilkan dalam media flashcard.
\end{abstract}

Kata Kunci: matematika permulaan; media flashcard; anak usia dini

\begin{abstract}
The ability of early childhood to understand early mathematics is still low. This is because the learning process in early childhood is not carried out in accordance with the child's age development. The purpose of this study is to describe the use of flashcard media in introducing early mathematics to early childhood. The research method used in this study uses literature study techniques by reviewing some literature from various existing sources that are tailored to the research topic. The data analysis technique used in this study consisted of three stages, namely data reduction, data presentation, and leveraging or drawing conclusions. The research results obtained in this study using flashcard media can help children understand early mathematics such as the concept of numbers and geometry. This is because the flashcard media displays images of basic geometric shapes that have a number in accordance with the symbol numbers 1-10, so that children can easily understand the meaning of the numbers 110 based on the number of quantities of the basic geometric shape images that are inserted into the flashcard media.
\end{abstract}

Keyword: early mathematics; flashcard media; early childhood.

Copyright (c) 2021 Idzni Azhima, R. Sri Martini Meilanie, Agung Purwanto

$\triangle$ Corresponding author:

Email Address : idzniazhima77@gmail.com (Medan, Indonesia)

Received 28 January 2021, Accepted 9 February 2021, Published 10 February 2021 


\section{PENDAHULUAN}

Pendidikan anak usia dini merupakan suatu upaya pemberian stimulasi oleh orang tua ataupun pendidik yang ditujukan bagi anak sejak lahir sampai dengan usia enam tahun untuk membantu pertumbuhan dan perkembangan jasmani dan rohani anak, serta menumbuhkembangkan aspek kognitif, bahasa, fisik motorik, sosial emosional, nilai agama dan moral, dan seni sehingga anak akan berkembang secara optimal dan memiliki kesiapan dalam memasuki pendidikan lebih lanjut. Pada usia ini pula, anak berada pada masa emas atau golden age yang merupakan saat paling tepat untuk mengembangkan seluruh aspek perkembangan pada anak usia dini, salah satunya yaitu aspek perkembangan kognitif yang termasuk di dalamnya pemahaman tentang konsep matematika.

Kemampuan matematika pada anak di Indonesia menurut hasil survey PISA masih tergolong rendah. PISA (Programme for International Student Assessment) merupakan program untuk mengukur prestasi bagi anak usia 15 tahun pada bidang kemampuan matematika, sains, dan literasi membaca (Hewi \& Shaleh, 2020). Pada tahun 2018 untuk kategori matematika, Indonesia berada di peringkat 7 dari bawah (73) dengan skor rata-rata 379 (Tohir, 2020). Menurut Hewi \& Shaleh (2020), pendidikan yang paling awal di tempuh oleh anak yaitu pendidikan anak usia dini yang dapat memperbaiki hasil penilaian PISA pada setiap bidang, termasuk bidang matematika. Hal ini dikarenakan fokus pembelajaran yang ada di pendidikan anak usia dini yaitu pemberian stimulasi pada aspek-aspek perkembangan yang ada pada anak usia dini secara holistik integratif, mulai dari mempelajari literasi membaca (bahasa), literasi matematika dan literasi sains (Hewi \& Shaleh, 2020). Selain itu, menurut Maryatun (2016) menegaskan bahwa keberadaan pendidikan anak usia dini sangat vital bagi kemampuan anak-anak Indonesia, karena PAUD adalah peletak dasar pertama bagi perkembangan anak (Maryatun, 2016). Dengan demikian, dapat disimpulkan bahwa, mengembangkan kemampuan matematika pada anak sejak dini dapat berpengaruh pada kemampuannya kelak di jenjang pendidikan lebih lanjut.

Berdasarkan uraian diatas, dapat dikatakan bahwa kemampuan siswa pada bidang matematika masih tergolong rendah. Hal ini disebabkan karena pada dasarnya kemampuan matematika pada anak tidak dikembangkan secara optimal sejak dini. Oleh karena itu, pengenalan konsep matematika tersebut tentunya diberikan sesuai dengan tingkat perkembangan usianya dan juga melalui pembelajaran yang menarik serta menyenangkan bagi anak. Pendidikan matematika penting untuk diberikan kepada anak sejak dini karena akan berpengaruh pada keberhasilannya kelak di jenjang pendidikan yang lebih tinggi. Sebagaimana menurut pendapat Gormley; Ludwig \& Philips dalam (Özçakır et al., 2019) bahwa pendidikan matematika awal bagi anak-anak usia dini dapat menjadi dasar bagi keberhasilan akademis di jenjang pendidikan yang lebih tinggi. Artinya, mengenalkan matematika pada anak sejak dini, dapat membantu keberhasilan pada bidang matematika di jenjang pendidikan yang lebih tinggi.

Menurut pendapat Suyadi dan Masnipal dalam (Kurniawan et al., 2019), kemampuan kogintif termasuk konsep matematika permulaan dapat dikenalkan sejak dini yaitu sejak usia 4-5 tahun yang konsep tersebut terdiri dari beberapa hal yaitu tentang konsep warna, bentuk, ukuran, pola, dan ruang. Selanjutnya, menurut The National Council Teachers of Mathematics (NCTM) terdapat lima konsep matematika permulaan yang dapat dikenalkan kepada anak, yaitu: bilangan dan operasi bilangan, aljabar, geometri, pengukuran, analisis data serta probabilitas (Hapsari et al., 2019). Beberapa karakteristik konsep matematika yang dapat dipelajari oleh anak menurut Charlesworth yaitu (1) korespondensi satu-satu; (2) menghitung; (3) mengklasifikasi; (4) mengukur (Charlesworth, 2011). Menurut Liebeck dalam (Iswanti, 2014), matematika permulaan pada anak usia dini yaitu merupakan kegiatan mengklasifikasikan atau mengelompokkan benda, mampu mengasosiasikan suatu nama dengan kelompok benda atau memasangkan dan menghubungkan bilangan dengan benda. Mempelajari konsep matematika permulaan bagi anak usia dini merupakan suatu upaya stimulasi kemampuan berpikir anak agar memiliki kesiapan belajar pada jenjang pendidikan 
lebih lanjut, serta membantu anak dalam memecahkan masalah secara nyata. Hal ini sejalan dengan pendapat (Sujiono, 2011) yang menyebutkan bahwa dengan mempelajari matematika merupakan salah satu cara dalam melatih kemampuan anak untuk dapat berpikir secara logis dan sistematis. Selain itu menurut (Brewer, 2013), matematika adalah cara memandang dunia dan pengalaman mereka di dalamnya, cara memecahkan masalah secara nyata, juga pemahaman tentang bilangan, operasi pada bilangan, fungsi dan hubungan, probabilitas dan pengukuran.

Pengenalan konsep matematika pada anak usia dini dapat dilakukan dengan menggunakan media-media yang menarik dan sesuai dengan perkembangan usia anak. Media pembelajaran merupakan hal yang penting digunakan dalam pelaksanaan proses pembelajaran pada anak usia dini. Selain dapat menarik perhatian anak, juga dapat membantu anak memahami konteks pembelajaran dengan mudah. Sejalan dengan pendapat Efendi dalam (Patria \& Iriyanto, 2014) menggunakan media pembelajaran secara tepat dan bervariasi dapat menimbulkan semangat dan ketertarikan anak dalam suatu aktivitas dan memungkinkan anak belajar sesuai dengan minat dan kemampuannya. Salah satu media yang dapat digunakan untuk mengenalkan matematika permulaan pada anak usai 4-5 tahun yaitu dengan menggunakan media flashcard.

Media flashcard merupakan salah satu bentuk media visual yang berbentuk kartu bergambar. Kartu ini digunakan dengan cara diperlihatkan kepada anak secara cepat. Sebagaimana yang dikutip oleh (Mansyur, 2018) bahwa flashcard adalah kartu bergambar yang dilengkapi kata-kata, yang diperkenalkan oleh Glenn Doman yang merupakan seorang dokter ahli bedah otak dari Philadelphia, Pennsylvania, yang menurutnya flashcard ini digunakan dengan cara diperlihatkan kepada anak dan dibacakan secara cepat. Kemudian, menurut Ratnawati dalam (Rahman et al., 2017), media flashcard dapat merangsang anak agar lebih cepat mengenal angka, membuat minat anak semakin kuat menguasai konsep bilangan, serta merangsang kecerdasan dan ingatan anak. Dengan demikian, penggunaan media flashcard dapat membantu anak mengenal konsep matematika permulaan seperti konsep bilangan dan geometri dengan menampilkan angka dan gambar-gambar bentuk dasar geometri, serta menampilkan benda-benda yang memiliki bentuk seperti bentuk dasar geometri. Beradasarkan latar belakang tersebut, penulis akan menyajikan telaah dari beberapa literatur tentang penggunaan media flashcard untuk mengenalkan matematika permulaan pada anak usia dini.

\section{METODOLOGI}

Penelitian ini merupakan penelitian kajian pustaka dengan menelaah beberapa literatur dari berbagai sumber seperti artikel jurnal dan buku. Menurut (Zed, 2014), studi kepustakaan adalah serangkaian kegiatan yang berkenaan dengan metode pengumpulan data pustaka, membaca, dan mencatat serta mengolah bahan penelitian yang memanfaatkan sumber perpustakaan untuk memperoleh data penelitiannya tanpa memerlukan riset lapangan. Menurut (Nazir, 2011) studi kepustakaan adalah teknik pengumpulan data dengan melakukan studi penelaahan terhadap beberapa buku, literatur, catatan, dan laporan yang ada hubungannya dengan masalah yang dipecahkan. Dengan demikian, penelitian studi kepustakaan merupakan suatu penelitian yang proses pengumpulan datanya dilakukan melalui telaah beberapa literatur yang dapat diambil dari berbagai sumber seperti buku ataupun artikel ilmiah yang berkaitan dengan permasalahan penelitian tanpa memerlukan riset lapangan. Penelitian studi kepustakaan ini bersifat kualitatif deskriptif, sehingga hasil dari telaah literatur dideskripsikan secara rinci agar dapat dipahami dengan mudah oleh pembaca. Penelitian ini menggunakan sumber data sekunder, yaitu dengan mengkaji beberapa literatur yang sesuai dengan topik penulisan artikel yaitu mengenai media flashcard dan matematika permulaan anak usia dini. Hasil dari beberapa literatur yang telah ditelaah, akan digunakan untuk mendeskripsikan penggunaan media flashcard dalam mengenalkan matematika permulaan pada anak usia dini. Adapun langkah-langkah dalam penelitian studi 
literatur menurut Kuhlthau (2002) dalam (Mirzaqon \& Purwoko, 2017) sebagaimana dapat dilihat pada gambar 1.

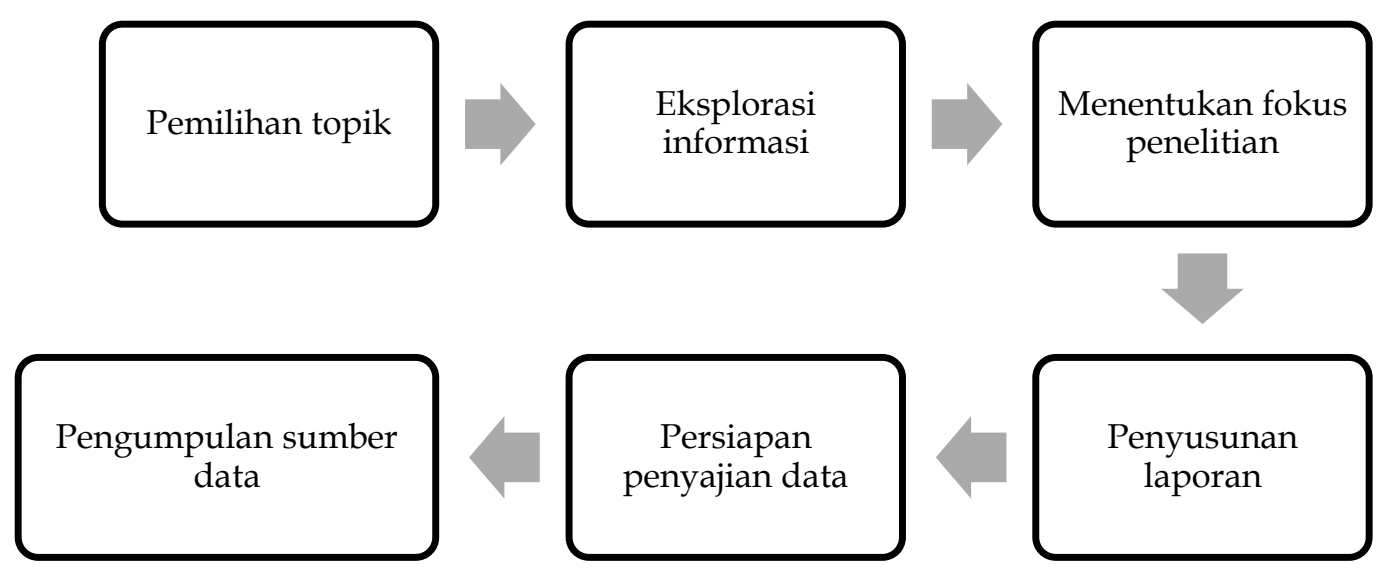

Bagan 1. Langkah-langkah penelitian studi literatur

\section{HASIL DAN PEMBAHASAN \\ Matematika Permulaan}

Matematika merupakan salah satu konteks ilmu pengetahuan yang termasuk dalam aspek perkembangan kognitif pada anak usia dini. Istilah matematika berasal dari kata Yunani yaitu mathein atau mathenein yang berarti mempelajari (Fitria, 2013). Sementara itu, menurut Kamus Besar Bahasa Indonesia (KBBI), matematika diartikan sebagai ilmu tentang bilanganbilangan, hubungan antara bilangan, dan prosedur operasional yang digunakan dalam penyelesaian masalah bilangan (Jannah, 2011). Dapat dipahami, bahwa sasaran dari matematika adalah meliputi bilangan serta hubungan antar bilangan. Kemudian menurut National Council of Teacher of Mathematics (NCTM), mengatakan bahwa matematika sangat erat kaitannya dengan angka (Handayani, 2018). Namun, menurut James dalam (Jannah, 2011), matematika dapat diartikan sebagai ilmu logika mengenai bentuk, susunan, besaran, dan konsep-konsep yang saling berhubungan satu sama lain. Berdasarkan pendapat James, dapat dipahami bahwa dalam matematika tidak hanya sekedar mempelajari bilangan dan lambang bilangan, tetapi juga mengenal tentang bentuk, susunan, besaran, dan konsep-konsep yang saling berhubungan.

Menurut Sujiono (2011), mempelajari matematika merupakan salah satu cara dalam melatih kemampuan anak untuk dapat berpikir secara logis dan sistematis. Adapun tujuan dari pembelajaran matematika pada anak usia dini menurut Rachmawati; Clement \& Samara dalam (Maulana, 2019) yaitu untuk menstimulasi kemampuan berpikir anak agar memiliki kesiapan dalam belajar matematika pada tahap selanjutnya, sehingga anak mampu menguasai berbagai pengetahuan dan keterampilan matematika yang memungkinkan mereka untuk mampu memecahkan masalah dalam kehidupan sehari-hari.

Dengan demikian, dapat diartikan bahwa matematika adalah suatu ilmu pengetahuan yang mempelajari tentang bilangan dan operasionalnya mulai dari yang konkret sampai dengan yang abstrak yang dapat melatih anak berpikir secara logis dan sistematis untuk dapat memecahkan masalah dalam kehidupan sehari-hari.

The National Council Teachers of Mathematics (NCTM) menyebutkan bahwa terdapat lima konsep matematika yang dapat dikenalkan kepada anak, yaitu: bilangan dan operasi bilangan, aljabar, geometri, pengukuran, analisis data serta probabilitas (Hapsari et al., 2019). Namun pada anak usia dini, dua konsep matematika yang utama untuk dikenalkan yaitu konsep bilangan dan geometri. Sejalan dengan The National Research Council Committee on Early Childhood Mathematics, berdasarkan hasil penelitiannya mengatakan bahwa terdapat dua 
bidang atau konsep yang menjadi fokus dalam pendidikan matematika permulaan pada anak usia dini, yaitu konsep bilangan dan geometri (Charlesworth \& Lind, 2012).

The Early Math Collaborative-Erikson Institute's (TEMCEI) dalam (Kermani, 2017), mengartikan angka atau lambang bilangan adalah kemampuan untuk memahami kuantitas suatu himpunan dan nama yang terkait dengan jumlah itu. Jadi, bilangan adalah suatu konsep matematika yang melambangkan kuantitas atau banyaknya suatu benda (seperti, * = satu bintang, ** = dua bintang, dst). Sedangkan lambang bilangan adalah suatu tanda atau lambang yang digunakan untuk melambangkan suatu bilangan (seperti, $1=$ satu, 2 = dua, dst). Sementara itu, Lestari (2011) menyatakan bahwa pengenalan konsep bilangan pada anak usia dini dapat dilakukan melalui tiga tahap, yaitu (1) membilang, yaitu menyebutkan bilangan berdasarkan urutan, (2) mencocokkan setiap angka dengan benda yang sedang dihitung, (3) membandingkan antara kelompok benda satu dengan kelompok benda yang lain untuk mengetahui jumlah benda yang lebih banyak, lebih sedikit, atau sama (Mulyati et al., 2019).

Sementara itu, menurut Bird dalam (Atmaja, 2017), geometri adalah bagian dari matematika yang membahas mengenai titik, garis, bidang, dan ruang. Kemudian, Lestari dalam (Novita, Putra, Rosayanti, \& Fitriani, 2018) menjelaskan bahwa dalam pendidikan anak usia dini, pemahaman tentang geometri didefinisikan sebagai kemampuan anak-anak untuk mengenali, menunjuk, menyebutkan dan mengumpulkan benda-benda di sekitarnya berdasarkan pada bentuk-bentuk geometri, seperti lingkaran, segitiga, dan segiempat. Khaleel dalam (Almohtadi et al., 2019) menekankan bahwa anak-anak harus dapat mengenali prinsipprinsip geometri seperti mengidentifikasi dan menggambar bentuk dasar geometri, membedakan antara bentuk dua dan tiga dimensi, dan membandingkan antara semua bentuk selama tahun-tahun usia dini.

Berdasarkan uraian di atas dapat disimpulkan bahwa matematika permulaan adalah pengenalan konsep-konsep matematika yang sederhana mulai dari hal yang konkret sampai dengan yang abstrak dan anak mampu untuk menerapkannya dalam kehidupan sehari-hari, yang meliputi konsep bilangan dan geometri.

\section{Media Flashcard}

Salah satu strategi guru untuk menciptakan pembelajaran yang menarik yaitu dengan menggunakan media. Media merupakan sebuah alat peraga atau perantara yang dapat digunakan untuk menyampaikan pesan atau informasi. Penggunaan media dalam proses pembelajaran dapat memudahkan guru menyampaikan materi serta pembelajaran menjadi lebih efektif dan efisien. Selain itu penggunaan media dalam kegiatan belajar dapat membantu anak memahami materi dengan mudah dan menambah minat belajar anak sehingga menjadikan anak lebih aktif.

Menurut Briggs dalam (Fadillah, 2017) mengatakan bahwa media adalah segala alat fisik yang dapat menyajikan pesan serta memotivasi siswa untuk belajar. Sanaky mendefinisikan media pembelajaran adalah alat yang berfungsi dan dapat digunakan untuk menyampaikan pesan pembelajaran (Sanaky, 2013). Selanjutnya, menurut Musfiqon dalam (Suryani et al., 2018), media pembelajaran merupakan alat bantu yang berfungsi untuk menjelaskan sebagian dari keseluruhan program pembelajaran yang sulit dijelaskan secara verbal. Selain itu, Sadiman, A.S. dalam (Fadillah, 2017) berpendapat bahwa media adalah segala sesuatu yang dapat digunakan untuk menyampaikan pesan dari pengirim ke penerima sehingga dapat merangsang pikiran, perasaan, perhatian dan minat serta perhatian siswa sedemikian rupa sehingga proses belajar terjadi.

Media pembelajaran yang dapat digunakan dalam kegiatan belajar terdiri dari beberapa kategori. Menurut Leshin, Pollock, \& Reigeluth dalam (Hamid et al., 2020) mengklasifikasikan media pembelajaran menjadi 5 jenis, yaitu 1) media berbasis makhluk hidup, 2) media berbasis cetak, 3) media berbasis visual, 4) media berbasis audio visual, dan 5) media berbasis komputer. Secara umum, menurut Satrianawati (2018), media dapat dibagi 
menjadi 4 jenis, yaitu 1) media visual, 2) media audio, 3) media audio visual, dan 4) multimedia.

Dengan demikian, berdasarkan pendapat ahli di atas, dapat dikatakan bahwa media pembelajaran adalah suatu alat peraga yang digunakan oleh guru untuk menyampaikan materi pelajaran sehingga mempermudah anak dalam memahami materi yang diajarkan.

Menurut (Olawale, 2013), terdapat beberapa contoh media pembelajaran seperti bagan, peta, diagram, komik, model, bola dunia, slide, strip film, televisi, kaset radio, video, perekam, bioskop, sistem alamat publik, laboratorium dan museum, flashcard, papan flanel, papan kartu, komputer, dll. Dari berbagai macam media tersebut, media yang dapat digunakan dalam proses pembelajaran pada anak usia dini yaitu media flashcard. Media flashcard merupakan salah satu bentuk media visual yang berbentuk kartu bergambar. Disebut dengan flashcard, karena kartu ini digunakan dengan cara diperlihatkan kepada anak secara cepat. Sebagaimana yang dikutip oleh (Mansyur, 2018) bahwa flashcard adalah kartu bergambar yang dilengkapi kata-kata, yang diperkenalkan oleh Glenn Doman yang merupakan seorang dokter ahli bedah otak dari Philadelphia, Pennsylvania, yang menurutnya flashcard ini digunakan dengan cara diperlihatkan kepada anak dan dibacakan secara cepat.

Menurut Azabdaftari dan Mozaheb dalam (Taghizadeh et al., 2017), media flashcard adalah sebuah kartu yang berisikan kata, kalimat, atau gambar sederhana. Selanjutnya, menurut Asyhar dalam (Asmodilasti \& Suparno, 2018) menjelaskan bahwa flashcard adalah media pembelajaran yang termasuk dalam jenis media visual, khususnya untuk mengkomunikasikan pesan dan dapat digunakan untuk mengungkapkan fakta melalui penggunaan kata-kata, angka dan simbol. Sementara itu menurut (Susilana \& Riyana, 2009), flashcard adalah media pembelajaran dalam bentuk kartu bergambar yang berukuran $25 \times 30$ $\mathrm{cm}$, dengan gambar-gambar yang ditempel pada lembaran-lembaran flashcard yang dilengkapi dengan keterangan dari gambar tersebut.

Keunggulan dari media flashcard menurut Indriana dalam (Rejeki et al., 2018) yaitu, (a) mudah dibawa kemana-mana karena ukurannya tidak terlalu besar; (b) praktis dalam membuat dan menggunakannya, sehingga anak dapat belajar dengan baik menggunakan media ini; (c) mudah diingat karena kartu ini sangat menarik, berisi huruf atau angka, sederhana, merangsang otak lebih lama mengingat pesan pada kartu; (d) sangat menyenangkan untuk digunakan sebagai media pembelajaran, dalam bentuk permainan. Selain itu, keunggulan lain dari penggunaan media flashcard dalam proses pembelajaran menurut (Pradana \& Gerhani, 2019) adalah kegiatan belajar lebih efektif dan efisien, berdaya guna, sensibel, serta menarik dan menyenangkan.

\section{Penggunaan Media Flashcard untuk Mengenalkan Matematika Permulaan pada Anak Usia Dini}

Menggunakan media flashcard dalam kegiatan belajar anak usia dini dapat membantu mengembangkan aspek perkembangan anak, salah satunya yaitu aspek perkembangan kognitif. Dalam aspek perkembangan kognitif tersebut mencakup tentang pemahaman anak pada konsep matematika. Wahono (2016) mengatakan bahwa media flashcard merupakan media yang dapat digunakan untuk menanamkan konsep bilangan pada anak usia dini (Wahono, 2016). Gambar-gambar pada media flashcard dikelompokkan dalam beberapa seri, seperti binatang, buah-buahan, warna, bentuk, huruf, angka, profesi, dan sebagainya. menurut Ratnawati dalam (Rahman et al., 2017), media flashcard dapat merangsang anak agar lebih cepat mengenal angka, membuat minat anak semakin kuat menguasai konsep bilangan, serta merangsang kecerdasan dan ingatan anak. Menurut Rahman dalam (Susanto, 2011), melalui penggunaan flashcard, anak mampu mengembangkan kemampuan kognitifnya dengan baik, memiliki konsep berhitung dengan baik, dan dapat mengembangkan seluruh potensi yang dimiliki sesuai dengan kemampuannya.

Dengan demikian, dapat disimpulkan bahwa flashcard merupakan sebuah media yang berbahan dasar kartu berisikan gambar-gambar yang dilengkapi dengan kata atau kalimat 
yang digunakan untuk menyampaikan pesan dalam pembelajaran melalui penggunaan katakata, angka, atau simbol.

\section{SIMPULAN}

Mempelajari matematika sejak usia dini merupakan salah satu cara dalam melatih kemampuan anak untuk dapat berpikir secara logis dan sistematis, serta menstimulasi kemampuan berpikir anak agar memiliki kesiapan dalam belajar matematika pada tahap selanjutnya. Upaya yang dapat dilakukan dalam mengenalkan matematika pada anak usia dini yaitu dengan menggunakan media pembelajaran, seperti media flashcard. Hal ini dikarenakan tampilan dalam media flashcard berisikan huruf, angka, ataupun gambar bentuk geometri yang dapat mempermudah anak dalam mengingat serta memahami konsep bilangan dan geometri yang termasuk dalam konsep matematika permulaan.

\section{UCAPAN TERIMA KASIH}

Penulis mengucapkan terima kasih kepada dosen pembimbing yang telah membantu dan memberikan dukungan dalam penyelesaian artikel ini sehingga menghasilkan penulisan yang lebih baik, serta ucapan terima kasih penulis sampaikan kepada berbagai pihak yang telah memberikan dukungan dalam proses menyelesaikan artikel ini.

\section{DAFTAR PUSTAKA}

Almohtadi, R., Aldarabah, I. T., \& Jwaifell, M. (2019). Effectiveness of Instructional Electronic Games in Acquisition of Geometry Concepts Among Kindergarten Children. Research on Humanities and Social Sciences, 9(12), 144-150. https:// doi.org/10.7176/RHSS

Asmodilasti, A., \& Suparno. (2018). Effectiveness of Flashcard in Improving Cognitive Ability of 5-6 Year Old Students. Advance in Social Science, Education and Humanities Research, 249. https://doi.org/https://doi.org/10.2991/secret-18.2018.16

Atmaja, J. R. (2017). Meningkatkan Kemampuan Mengenal Geometri Melalui Permainan Dakon Pada Anak Usia 4-5 Tahun. Jurnal Pelita PAUD, 1(2), 121-134. https:// doi.org/https:/ / doi.org/10.33222/ pelitapaud.v1i2.206

Brewer, J. A. (2013). Introduction to Early Childhood Education Preschool Through Primary Grades 6th Edition. Pearson Education Inc.

Charlesworth, R. (2011). Experiences in Math for Young Children. Cengage Learning.

Charlesworth, R., \& Lind, K. K. (2012). Math and Science for Young Children. Cengange Learning. Fadillah, M. (2017). Bermain dan Permainan Anak Usia Dini. Kencana.

Fitria, A. (2013). Mengenalkan dan Membelajarakna Matematika Pada Anak Usia Dini. Mu'adalah: Jurnal Studi Gender Dan Anak, 1(2). https://doi.org/DOI: http://dx.doi.org/10.18592/jsga.v1i2.675

Hamid, M. A., Ramadhani, R., Masrul, Juliana, Safitri, M., Munsarif, M., Jamaludin, \& Simarmata, J. (2020). Media Pembelajaran. Yayasan Kita Menulis.

Handayani, O. D. (2018). Pembelajaran Matematika Permulaan Melalui Kewirausahaan Pada Aktivitas Bercocok Tanam Pada Anak Usia Dini. PAUDIA, 7(2). https:// doi.org/10.26877/ paudia.v7i2.3270.

Hapsari, M. N., Ilhami, B. S., \& Agustina, Y. (2019). Dekak-Dekak Geometri, Media Pembelajaran untuk Mengenalkan Bentuk Geometri Pada Anak Kelompok A. Jurnal Golden Age, 3(01), 30-36. https:// doi.org/10.29408/goldenage.v3i01.1433.

Hewi, L., \& Shaleh, M. (2020). Refleksi Hasil PISA (The Programme For International Student Assesment): Upaya Perbaikan Bertumpu Pada Pendidikan Anak Usia Dini. Jurnal Golden Age, 4(1). http://www.ejournal.hamzanwadi.ac.id/index.php/jga/article/view/2018. https:// doi.org/10.29408/jga.v4i01.2018.

Iswanti. (2014). Peningkatan Pemahaman Konsep Bilangan Melalui Permainan 
Memasangkan. Jurnal Pendidikan Usia Dini, 8(2), 391-400.

Jannah, R. (2011). Membuat Anak Cinta Matematika dan Eksak Lainnya (p. 26). Diva Press.

Kermani, H. (2017). Computer Mathematics Games and Conditions for Enhancing Young Children's Learning of Number Sense. Malaysian Journal of Learning and Interactions, 14(2), 23-57. https://doi.org/10.32890/mjli2017.14.2.2.

Kurniawan, D. E., Dzikri, A., Widyastuti, H., Sembiring, E., \& Manurung, R. T. (2019). Smart mathematics : a kindergarten student learning media based on the drill and practice model. Journal of Physics: Conference Series. https://doi.org/10.1088/1742$6596 / 1175 / 1 / 012037$

Mansyur, U. (2018). Pembelajaran Inovatif Bahasa Indonesia di Sekolah Dasar. https://doi.org/10.31227/osf.io/fyr8g

Maryatun, I. B. (2016). Peran Pendidik PAUD dalam Membangun Karakter Anak. Jurnal Pendidikan Anak, 5(1). https:// doi.org/https:/ / doi.org/10.21831/jpa.v5i1.12370

Maulana, R. A. (2019). Math untuk Anak Usia Dini. IGI PD.

Mirzaqon, T. ., \& Purwoko, B. (2017). Studi Kepustakaan Mengenai Landasan Teori dan Praktik Konseling Expressive Writing. Jurnal BK Unesa, 8(1).

Mulyati, C., Muiz, D. A., \& Rahman, T. (2019). Pengembangan Media Papan Flanel untuk Memfasilitasi Kemampuan Konsep Bilangan Anak Pada Kelompok B. Jurnal Pendidikan Dan Konseling, 1(1). https:/ / doi.org/https:/ / doi.org/10.31004/jpdk.v1i1.362

Nazir, M. (2011). Metode Penelitian. Ghalia Indonesia.

Novita, R., Putra, M., Rosayanti, E., \& Fitriani, F. (2018). Design learning in mathematics education: Engaging early childhood students in geometrical activities to enhance geometry and spatial reasoning. Journal of Physics: Conference Series, 1088. https://doi.org/10.1088/1742-6596/1088/1/012016

Olawale, S. K. (2013). The Use of Instructional Materials for Effective Learning of Islamic Studies. Jurnal Jihat Al-Islam, 6(2).

Özçakır, B., Konca, A. S., \& Arıkan, N. (2019). Children's Geometric Understanding through Digital Activities: The Case of Basic Geometric Shapes. In International Journal of Progressive Education (Vol. 15, Issue 3). https:// doi.org/10.29329/ijpe.2019.193.8

Patria, D., \& Iriyanto, T. (2014). Penggunaan Media Papan Flanel Untuk Meningkatkan Hasil Belajar Mengenal Bilangan 1 Sampai 10 Siswa Kelas I SDLB. Jurnal Penelitian Dan Pengembangan Pendidikan Luar Biasa, 1(2).

Pradana, P. H., \& Gerhani, F. (2019). Penerapan Media Pembelajaran Flashcard untuk Meningkatkan Perkembangan Bahasa Anak. Journal of Education and Instruction, 2(1). https://doi.org/https://doi.org/10.31539/joeai.v2i1.587

Rahman, T., Sumardi, \& Fuadatun, F. (2017). Peningkatan Kemampuan Anak Usia Dini Mengenal Konsep Bilangan Melalui Media Flashcard. Jurnal PAUD Agapedia, 1(1), 118128. https:// doi.org/https:/ / doi.org/10.17509/jpa.v1i1.7167

Rejeki, H. I., Hidayah, R., Cendrawati, L., \& Juwarti. (2018). Improving The Quality of Science Learning Through Mind Mapping Model with Flashcard. International Conference on $\begin{array}{llll}\text { Science and } & \text { Education }\end{array}$ https://doi.org/https://doi.org/10.2991/iset-18.2018.47

Sanaky, H. A. . (2013). Media Pembelajaran Interaktif dan Inovatif. Kaukaba.

Satrianawati. (2018). Media dan Sumber Belajar. Deepublish.

Sujiono, Y. N. (2011). Metode Pengembangan Kognitif. Universitas Terbuka.

Suryani, N., Setiawan, A., \& Putria, A. (2018). Media Pembelajaran Inovatif dan Pengembangannya. Remaja Rosdakarya.

Susanto, A. (2011). Perkembangan Anak Usia Dini: Pengantar dalam Berbagai Aspeknya. Kencana Prenada Media Group.

Susilana, R., \& Riyana, C. (2009). Media Pembelajaran (Hakikat, Pengembangan, Pemanfaatan, dan Penilaian). Wacana Prima.

Taghizadeh, M., Vaezi, S., \& Ravan, M. (2017). Digital Games, Songs and Flashcards and Their 
Effects on Vocabulary Knowledge of Iranian Preschoolers. Internasional Journal of English Language \& Translation Studies, 5(4).

Tohir, M. (2020). Hasil PISA Indonesia Tahun 2018 Turun Dibanding Tahun 2015. Https://Www.Researchgate.Net/Publication/337717927 Hasil. https:/ / doi.org/10.17605/OSF.IO/8Q9VY

Wahono. (2016). Design Inovasi Media Flashcard Mahasiswa PG PAUD UMSURABAYA untuk Menanamkan Konsep Membilang Angka 1-9 Pada Anak Usia Dini. Jurnal Pedagogi, 2(3).

Zed, M. (2014). Metode Penelitian Kepustakaan. Yayasan Obor Indonesia. 